\title{
Iris Fixated Intraocular Lens Implantation
}

\author{
Mustafa Tașeli (1), Erol Dülger (1) \\ Department of Opthalmology, Near East University School of Medicine, Nicosia, Cyprus
}

ORCID IDs of the authors: M.T. 0000-0003-1488-23I8; E.D. 0000-0002-3145-6460.

Cite this article as: Tașeli M, Dülger E. Iris Fixated Intraocular Lens Implantation. Cyprus J Med Sci 2018; 3(3): 197-9.

\begin{abstract}
Management of dislocated lens is one of the challenges faced in ophthalmology practice. Here we reported the case of patient with dislocated lens and its management with pars plana anterior vitrectomy, intraocular lens (IOL) exchange, and fixation of new 3 pieces $\mathrm{IOL}$ to iris with a Siepser suture technique.
\end{abstract}

Keywords: Dislocated IOL, iris fixated IOL, pars plana anterior vitrectomy

\section{INTRODUCTION}

Dislocated Intraocular lens (IOL) might be presented during or after cataract surgery, trauma, insufficient capsular support, or zonular dehiscence (I). There are several surgical methods for the management of dislocated IOL. The ones applied mostly are anterior chamber IOL, scleral fixation of same or new IOL, and iris fixation of same or new IOL (I-5). Here we reported the management of the case of a patient with traumatic dislocated IOL with pars plana anterior vitrectomy and implantation of 3-piece IOL to iris.

\section{CASE PRESENTATION}

An 80 years old male patient complaining of decrease in sight in his right eye after accidental hit with a peanut was admitted to our department. He had a history of right eye cataract surgery 7 years ago. Physical findings revealed hand motion vision and dislocated IOL in his right eye; the left eye was normal. The patient underwent pars plana anterior vitrectomy, dislocated IOL explantation through corneal incision, and fixation of 3-piece posterior chamber IOL (Alcon Acrysof MA60AC, Alcon Laboratories, USA) to iris under general anesthesia. Initially, 2 transconjonctival 23-gauge (G) trocars were inserted at distance $3.5 \mathrm{~mm}$ periphery to the limbus. One of them was infusion for balanced salt solution (BSS, Alcon Laboratories, USA) and the other one was for vitrectomy probe. Then, pars plana anterior vitrectomy was performed. The vitreous around the dislocated IOL was cleared. Dislocated IOL was taken to the anterior chamber. Temporal corneal incision was performed with a corneal knife (Ophthalmic knife, MST 45 straight, Mani Inc., Japan) between 9 and I2 o'clock position. Dislocated IOL was explanted through corneal incision. Then new 3-piece IOL (Alcon Acrysof MA60AC, Alcon Laboratories, USA) was inserted into the anterior chamber through corneal incision (Figure la). The anterior chamber was filled with cohesive viscoelastic substance $(0.50 \mathrm{~mL}$ in volume; sodium chondroitin sulfate $4 \%$, sodium hyaluronate $3 \%$ with $27 \mathrm{G}$ canula, Viscoat, Alcon Laboratories, USA). Corneal incision was closed with 3 separate $10 / 0$ nylon sutures. One of thehaptic segments of IOL inserted to the posterior chamber. Paracentesis was made at I o'clock with a $20 \mathrm{G}$ MVR knife (MV2 20, Mani Inc., Japan) for the insertion of needle (Mani L2460, Mani Inc., Japan). A long curved needle was passed from paracentesis through the iris then under the haptic up to the anterior chamber and lastly went out through the cornea (Figure lb). Hook inserted through the paracentesis grasps the distal strand of the suture out of the eye. Distal strand forms a loop outside the eye adjacent to the proximal strand. The distal loop was grasped with a tying forceps, triple throw was made. So knot was slided by pulling proximal and distal strands. The hook was used again to create a loop of the distal strand through that proximal strand. Reverse single throw of the distal loop was made and the proximal strand was grasped to slide the distal loop, thus tightening the suture. A microscissor was used to cut suture ends (Figure lc). Other haptic segment of IOL was inserted into the posterior chamber and the long needle was passed from corneal incision, iris, under the haptic, and out from the limbal cornea (Figure Id). The Siepser knot suture technique was used to fixate the iris (Figure le). The optic segment of IOL was inserted into the posterior chamber behind the iris. Viscoelastic was cleared 

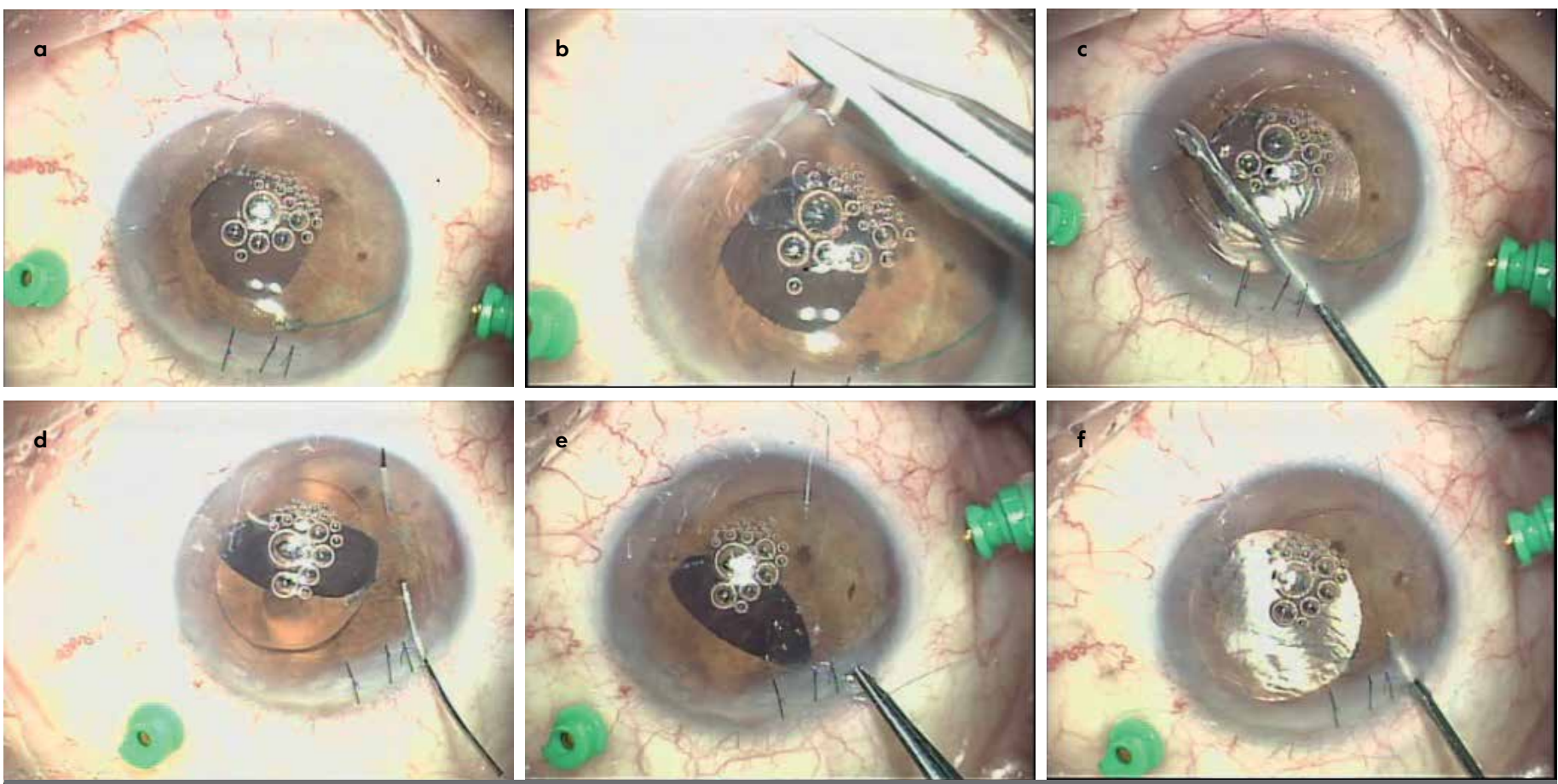

FIGURE I. a-f. Three-piece IOL insertion to the anterior chamber (a). Long curved needle passed from paracentesis through the iris then under the haptic up to the anterior chamber and cornea out of the eye (b). Microscissors used to cut the suture ends (c). Other haptic inserted into the posterior chamber and long needle passed through the corneal incision, iris, under the haptic, and out from the limbal cornea (d). Siepser knot suture technique used again to fixate iris $(e)$. Viscoelastic was cleared through paracentesis and trocars were removed $(f)$.

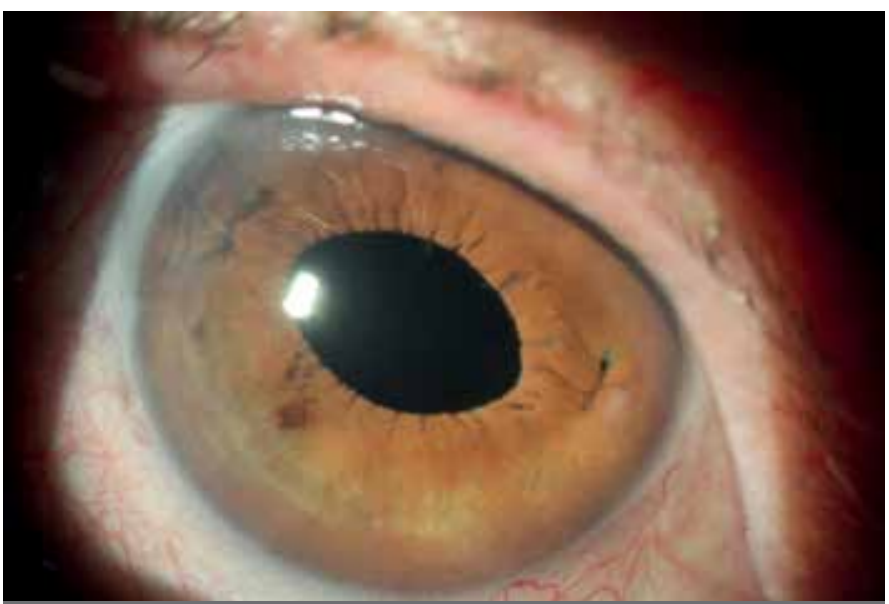

FIGURE 2. Postoperative one month later $\mathrm{OL}$ was well centered

and vision is $8 / 10$.

IOL: Intraocular lens.

through paracentesis and trocars were removed (Figure le). Mix of dexamethasone and gentamicin injected by subconjunctival route at the end of operation. After 3 months of operation vision was 0.8 with Snellen chart. IOL was centrally located. There was no pathologic fundus finding (Figure 2). Informed consent was obtained from the patient prior to the study.

\section{DISCUSSION}

Management of dislocated IOL is one of the challenges in ophthalmology practice. Each option has its advantages and disadvantages. Applying the anterior chamber IOL after removal of dislocated lens is easy, but this may cause corneal endothelial cell insufficiency that may result in bullous keratopathy and sight loss $(I, 3,4)$. Scleral fixated IOL implantation has advantages with less endothelial cell loss; however, tilted IOL and suture exposure are the major problems of this type IOL application (I). Iris fixated IOL application has advantages, such as less endothelial cell loss like scleral fixated IOL implantation and less tilted IOL compared with scleral fixated IOL, but contact of IOL may cause iris pigment discharge and an inflammatory reaction $(1,2,5)$. In our case, we preferred iris fixated IOL implantation with the Siepser knot technique with $10 / 0$ nylon suture, following pars plana vitrectomy and dislocated IOL exchange. We preferred this option to protect corneal endothelial cells, to decrease the risk of tilted $\mathrm{IOL}$, and to prevent the complications of other methods.

Management of dislocated IOL secondary to trauma, ruptured capsule, implantation of $\mathrm{IOL}$, and choice of $\mathrm{IOL}$ implantation method is one of the challenges in ophthalmology practice. Fixation of 3- piece IOL to iris with a Siepser knot of 10/0 nylon suture after pars plana vitrectomy and $\mathrm{IOL}$ exchange is an option for the management of such cases. To assess the safety of this method case series are needed.

Informed Consent: Informed consent was obtained from the patient who participated in this study.

Peer-review: Externally peer-reviewed.

Author Contributions: Concept - M.T., E.D.; Design -M.T., E.D.; Supervision - M.T., E.D.; Resource - M.T, E.D.; Materials - M.T.E.D.; Data Collection and/ or Processing - M.T.,E.D.; Analysis and/or Interpretation - M.T., E.D.; Literature Search - M.T.,E.D.; Writing -M.T., E.D.; Critical Reviews -M.T., E.D

Conflict of Interest: The authors have no conflicts of interest to declare.

Financial Disclosure: The authors declared that this study has received no financial support. 


\section{REFERENCES}

I. Wagoner MD, Cox TA, Ariyasu RG, Jacobs DS, Karp CL; American Academy of Ophthalmology. Intraocular lens implantation in the absence of capsular support: a report by the American Academy of Ophthalmology. Ophthalmology 2003; II0: 840-59. [CrossRef]

2. Faria MY, Ferreira NP, Canastro M. Management of dislocated intraocular lenses with iris suture. Eur J Ophthalmol 2017; 27: 45-8 [CrossRef]

3. Hennig A, Johnson GJ, Evans JR, Lagnado R, Poulson A, Pradhan D. Long term clinical outcome of a randomised controlled trial of anterior chamber lenses after high volume intracapsular cataract surgery. Br J Ophthalmol 200I; 85: II-7. [CrossRef]

4. Evereklioglu C, Er H, Bekir NA, Borazan M, Zorlu F. Comparison of secondary implantation of flexible open-loop anterior chamberand scleral-fixated posterior chamber intraocular lenses. J Cataract Refract Surg 2003; 29: 30I-8 [CrossRef]

5. Condon GP, Masket S, Kranemann C, Crandall AS, Ahmed II. Small-incision iris fixation of foldable intraocular lenses in the absence of capsule support. Ophthalmology 2007; ||4: I3||-8. [CrossRef] 